\title{
Probabilistic seismic hazard assessment for Nepal
}

\author{
H. Ram Parajuli ${ }^{1}$, J. Kiyono ${ }^{2}$, H. Taniguchi ${ }^{1}$, K. Toki $^{1}$ \\ \& P. Nath Maskey ${ }^{3}$ \\ ${ }^{1}$ Ritsumeikan Global Innovation Research Organization, \\ Ristumeikan University, Japan \\ ${ }^{2}$ Department of Urban Management, Kyoto University, Japan \\ ${ }^{3}$ Department of Civil Engineering, IOE, Tribhuvan University, Nepal
}

\begin{abstract}
Written history of great earthquakes in excess of magnitude M8 and recently identified 92 small faults around underlying big three fault systems parallel to the Himalayas show a high seismicity in Nepal. However, since faults are so closed that it is difficult to judge which earthquake belongs to which fault and even some of the faults do not hold earthquakes, the usual method of assigning the earthquakes to the nearest fault developing magnitude-frequency relationship is not applicable. Thus, an attempt has been made here to address the problem considering area sources with different densities at each location based upon historical earthquakes and faults which is real evidence of the seismicity of the region. Separate earthquake densities are calculated based upon historical earthquakes and maximum magnitudes of faults using the kernel estimation method which accounts the significance of both the number of earthquakes and size. Since there is no specific attenuation laws developed for the Himalayan region, five attenuation laws developed for seduction zone are selected and used, giving equal weight to all to minimize the uncertainties. Then, the probabilistic spectra for various return periods are calculated, compared with previous estimates and various aspects discussed.
\end{abstract}

Keywords: earthquakes, faults, Nepal, Himalaya, seismic hazard, spectra. 


\section{Introduction}

The collision of India into Asia, 50 million years ago, caused the Eurasian plate to crumble up and override the Indian plate [1]. After collision, the slow convergence of two plates over millions of years pushed up the Himalayas and the Tibetan plateau to their present heights. The Himalayas, approximately two thousand two hundred kilometres long, is the youngest and most fragile geology, and high rise mountain in the world, extends from west to the east of the northern part of Nepal. It is called Nepal Himalaya and approximately one thousand kilometres in length. Within the narrow width of Nepal (fig. 1), three fault systems, Main Central Thrust (MCT), Main Boundary Thrust (MBT) and Himalayan Frontal Thrust (HFT), pass east to west throughout the length of Nepal. Along the sides of these three greater fault systems and in the Tibetan Himalayan region, ninety two small faults have been identified [3]. Most of these

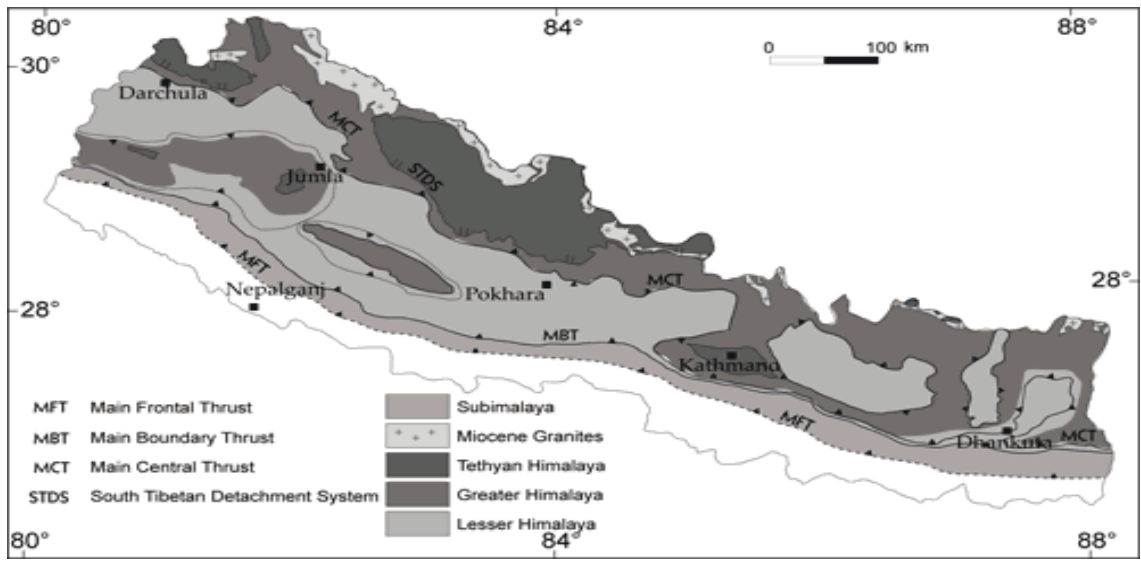

(a)

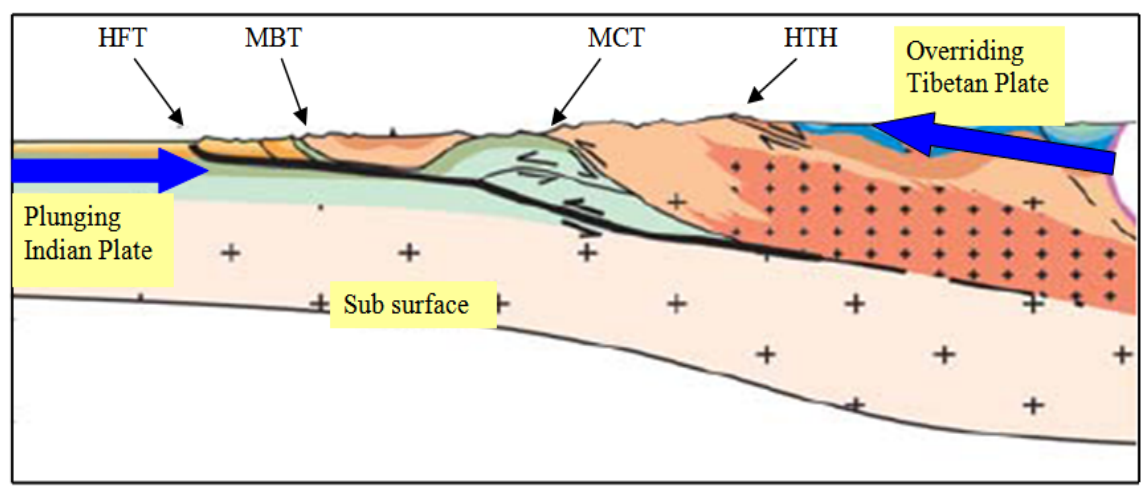

(b)

Figure 1: (a) Geological map of Nepal. (b) North-south cross section of Nepal showing depth and faulting systems after Avouac [2]. 
faults might have formed during the past 10 million years and lie in the interface of Indian and Tibetan plate. The geology of Nepal is also differed by the great faults. The southern part is plane with soft alluvium deposits, the middle part is low rise mountains and the northern part is high rise rocky mountains. The convergence of two plates has resulted many earthquakes in the past in excess of moment magnitude M8 [4, 5] indicates a high rate of deformation and seismicity in the region necessitating an urgent need of seismic hazard estimation and mitigation.

Some studies have also been done for Kathmandu and for Nepal. Hazard curves and risk consistent response spectrum was obtained by Maskey and Datta [6] for a typical location in the Kathmandu valley. Free field peak ground acceleration was obtained considering the soil non linearity. As a part of preparation of building code, seismic hazard mapping and risk assessment for Nepal [3] was done under the Ministry of Housing and Physical Planning of Nepal, which is a most specific document addressing the seismic hazard issue of Nepal. It has identified ninety two smaller faults within and around Nepal. The whole area has been divided into three sub zones depending on the earthquake density obtained from available and assumed earthquakes, however, details have not been provided on what basis earthquake data was considered. Seismic hazard assessment has been estimated considering both historical data and assigned characteristic earthquakes after subdividing it into twenty one small zones. It has assigned different coefficients for magnitude frequency relationship to the identified ninety two smaller faults, though details have not been given. BECA [3] further divides the whole study area into small area sources, assigns the different maximum magnitudes for each region, but no areas have a maximum magnitude greater than M8, whereas three earthquakes in excess of M8 have already occurred and one of which is also included in their catalogue. Distribution of earthquake densities in different sub-zones has not been well explained. Division of big area into three types of zones and considering uniform distribution of earthquakes within the zone smears out the earthquakes into greater area and the hazard estimates on that basis will result in always a low value. Another issue on that study is attenuation law. It has used the Kawashima et al. [7] equation. Large numbers of studies on developing attenuation laws have been done since then. Investigations regarding tectonic slip between Tibetan and Indian plates, earthquake size scaling relations have been undertaken on this decade. JICA [8] undertook a comprehensive study for disaster mitigation of Kathmandu valley. It has pointed out that risk at Kathmandu is so high that a great earthquake may occur any time. If an earthquake occurs, the damage scenario would be worst and Kathmandu valley could not function as a capital city. Recently, probabilistic seismic hazard assessment [9, 10] for Kathmandu and Nepal considering intra-plate rate observed from GIS information has been done. Recurrence rate of earthquakes has been raised by considering some fraction of intra-plate slip rate; however, what fraction is appropriate still remains a big question.

Major issues, such as advances in the development of ground motion equations, investigation of magnitude scaling of earthquakes in the Himalayan 
region and confirmation of location and size of the great 1505 earthquake, have been done after BECA [3]. Thus, a seismic hazard estimate addressing these issues has been presented here. This study covers formation of earthquake catalogue merging the data from various sources, development of magnitude frequency relationship at various locations of the rectangular grids and estimation of probabilistic peak ground and spectral accelerations at various natural periods of the structures.

\section{Earthquake catalogue and recurrences}

The historical earthquake data within $300 \mathrm{~km}$ away from the area enclosed by 26.5-30.5N latitude and 80-89E longitude through 2009 was collected. The earthquake catalogue was formed merging the data from U.S. Geological Survey [11], BECA [3], Ambraseys and Jackson [5], Pant [12], and Ambraseys and Douglas [13]. The earthquakes data have been reported in different magnitudes and in intensity scales. To make uniformity, all data were converted to the moment magnitude [14] using various relationships given in McGuire [15] and scaling relationship for Himalayan region [13]. Then, earthquake data is plotted (fig. 3) with the faults.

The usual practice for seismic hazard analysis is to allocate the earthquakes to the nearest faults, rearrange the data into various magnitude groups and year intervals, develop recurrence relationships, calculate mean rate of exceedences. However, the faults are so closed that it is difficult to judge which earthquake belongs to which fault. Furthermore there are two categories of faults - greater fault systems (MFT, MBT, MCT, and STDS-fig. 1) and smaller faults (92 as defined in BECA [3]). The smaller faults have been said to be part of the greater one, however, they might be multiple rupture segments of greater fault systems. If there were really faults, earthquakes should have occurred in the past. Some of the faults look empty. Even though the location of faults seems questionable, our study here is not to criticize that report, rather to take it as one of the references. If only the historical earthquake is considered, on the one hand, it is difficult to allocate them in the fault being close to multiple faults and on the other hand, some of the faults are empty, and some of them hold only few numbers of data which is insufficient to define the recurrence relationship for individual faults. From engineering prospective, peak ground or spectral acceleration and time history of ground motions at a particular site are necessary and important for design of new and strengthening of existing structures rather than detailing individual small faults. Thus, whole area is divided into grids and cells at intervals of 0.5 and 1.0 degrees in latitude and longitude respectively. Centre of each cell is considered a site. All the earthquakes greater than magnitude M4 inside $300 \mathrm{~km}$ radius of each site are grouped into $0.5 \mathrm{M}$ interval. Earthquake data are not uniformly distributed, only few records are available in early periods and numbers of records have been increasing towards end. In order to do completeness analysis [16] of data, events have been grouped into small interval of time. Each magnitude ranges have been judged separately and the rates of earthquakes exceeding each magnitude are calculated for all the sites the slope 
(represented by b value) is almost unity in the eastern side whereas it is higher in the western part. This means sufficient data are available in the eastern part than in the western side, either earthquake data is missing or big quake may occurs soon as the intra plate slip deficit [17] exist in the region.

\section{Attenuation of ground motion}

Ground motion attenuation relations so far developed, can be categorized into four groups, shallow crustal earthquakes in active regions, shallow crustal earthquakes in stable regions, extensional environments and subduction zones focusing America and Japan where big earthquake database is available. Specially, no earthquake attenuation relations have been developed for the Himalayan region, so far specially. Because of unavailability of sufficient data, here, instead of developing new equation for the region, attenuation equations among already developed equations for subduction zone (Crouse [18], Fukushima and Tanaka [19], Molas and Yamazaki [20], Young et al. [21], Gregor et al. [22] Atkinson and Boore [23], Atkinson and Boore [24], Kanno et al. [25], Zhao et al. [26]) which support the tectonics, geology and faulting system are studied.

Youngs et al. [21] has been developed from worldwide seismic environment including Crouse [18] catalogue. Zhao et al. [26] relation uses Fukushima and Tanaka [19], and Molas and Yamazaki [20] and is derived from Japanese earthquake database. Kanno et al. [25] relationship has also been developed based on Japanese catalogue adding shallow crustal earthquakes from outside Japan. Atkinson and Boore $[23,24]$ compiled the database of both Youngs et al. [21] and Crouse [18], added many recent earthquakes data from Japan through 2001, formed four times big database for subduction zone events and developed new ground motion relation. Gregor et al. [22] relation has been also developed for Cascadia subduction zone. Both attenuation equations have focused on Cascadia fault geometry and ground motion parameter is estimated based on fault distances. Considering these five equations represent typical seismic environment - Youngs et al. [21], Gregor et al. [22], and Atkinson and Boore [23, 24], Kanno et al. [25] and Zhao et al. [26] attenuation laws are selected for this study. Among them, Atkinson and Boore [23, 24] predict lowest and Zhao et al. [26] highest values. There is no certainty that future earthquake obey any particular attenuation law. Thus, seismic hazard is estimated considering all attenuation giving equal weight.

In subduction zones, there is possibility of occurring both interface and intraplate earthquakes. None of the past earthquakes in the Himalayan regions have been categorized as interface or intra-plate earthquake. Regarding the information available in the region, there is shallow angle thrust faults which is very similar situation of subduction interface earthquakes as in the other part of the world. For intra-plate, earthquakes are basically categorized by deep focus and volcanic activities. There are no reported evidences of volcanic activities in the central Himalayas. So, subduction interface ground motion relations are considered in this study. 


\section{Seismic hazard assessment}

For each site, $600 \mathrm{kmX} 600 \mathrm{~km}$ area is taken as source and divided into smaller

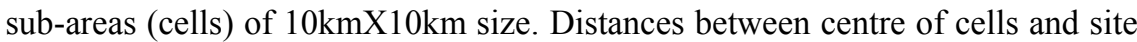
are calculated. Only the cells within $300 \mathrm{~km}$ radius are considered to make the recurrence equation applicable. The mean rate (eqn. (1)) of exceeding particular value of acceleration is calculated by summing up all the probabilities of occurrences of earthquakes given magnitudes and distances (Kramer [32]).

$$
v_{y^{*}}=\sum_{i=1}^{N_{s}} v_{i_{M \min }} \iint P\left[Y>y^{*} \mid m, r\right] f_{M i}(m) f_{R i}(r) d m d r
$$

where $\mathrm{N}_{\mathrm{s}}$ is number of sources in the region, $v_{i_{M \min }}=\exp \left(\alpha_{i}-\beta_{i} m_{\min }\right)$ is total rate of exceedences of threshold magnitude $(\mathrm{M}=5.0$ is taken in this study), with $\alpha=2.303 a, \beta=2.303 b \cdot P\left[Y>y^{*} \mid m, r\right]$ is conditional probability that is chosen acceleration exceeded for a given magnitude (M) and distance (R), and $f_{M i}(m)$ and $f_{R i}(r)$ are probability density functions for magnitude and distance respectively. Here, $\mathrm{M}$ and $\mathrm{m}$ are used as random variable and specific value for magnitude respectively. The probability density function for Gunterberg-Richter law with lower and upper bound magnitudes is expressed in eqn. (2).

$$
f_{M}(m)=\frac{\beta \exp \left[-\beta\left(m-m_{\min }\right)\right]}{1-\exp \left[-\beta\left(m_{\max }-m_{\min }\right)\right]}
$$

Since recurrence relation is developed for $300 \mathrm{~km}$ square area, it is applicable for all the cells around the site. However, the earthquake data is not uniformly distributed over whole area (fig. 2). Higher concentration exists in the narrow zone along MCT and MBT than Tibetan Himalayan and lowest concentration is in the southern alluvium.

\subsection{Earthquake densities}

Earthquake density is simply number of earthquakes per unit area. However, size of earthquake makes major influence in terms of effects. Effect of a single big event would be far greater than thousands of smaller events. Thus, activity rate based upon size of earthquake is calculated using Kernel estimation method (Woo [27]). Considering total rate around the particular site is unity, fraction of activity rate which called earthquake density here, for all the sources around the site is calculated depending upon the numbers and size of the earthquakes available in and nearby cells. The mean activity rate $\lambda(m, x)$, at a cell is taken as a kernel estimation sum considering the contribution of $\mathrm{N}$ events inversely weighted by its effective return period which satisfies the condition (eqn. (3)) that can be obtained from eqns. (4)-(7).

$$
\begin{array}{r}
r \leq h\left(m_{j}\right) \\
\lambda(m, x)_{i}=\sum_{j=1}^{N} \frac{K\left(m_{j}, r_{j}\right)}{T\left(r_{j}\right)}
\end{array}
$$




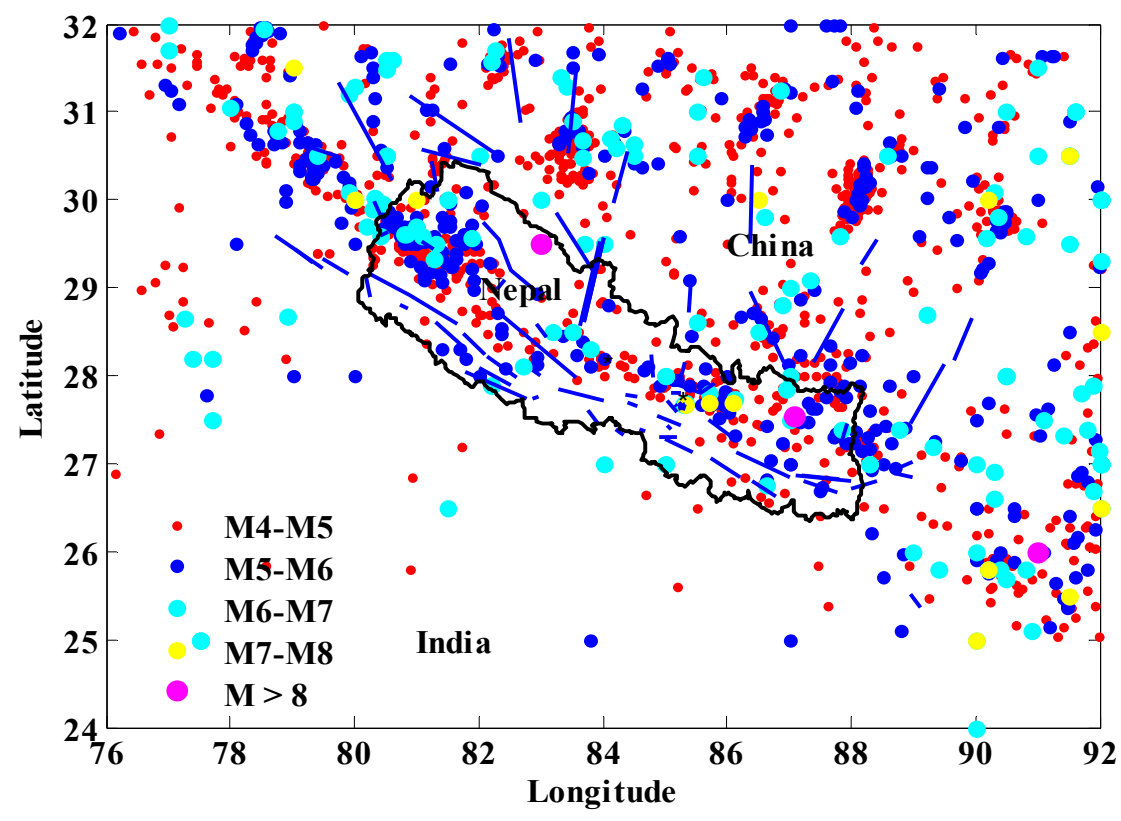

Figure 2: Historical earthquakes (points) and faults (line).

$$
\begin{gathered}
K(m, r)_{j}=\left[\frac{D}{2 \pi h\left(m_{j}\right)}\right]\left\{\frac{h\left(m_{j}\right)}{r_{j}}\right\}^{2-D} \\
h\left(m_{j}\right)=H \exp \left(C m_{j}\right) \\
\rho_{i}=\frac{\lambda(m, x)_{i}}{\sum_{i=1}^{N_{s}} \lambda(m, x)_{i}}
\end{gathered}
$$

where, $K(m, x)$ is kernel function, $T(r)$ is return period of the event located at distance from $\mathrm{r}, h(m)$ is kernel band width scaling parameter shorter for smaller magnitude and vice vice-versa, which may be regarded as a fault length (Chen et. al. [28]) and $\mathrm{D}$ is fractal dimension, is taken as 1.7. $\mathrm{H}$ and $\mathrm{C}$ are constants equal to 1.45 and 0.64 . From fig. 2 , we can see that the distribution of earthquakes are not only uneven, none of data has fallen near some faults. The faults are geological evidences of sources of earthquakes, even though, earthquakes data may not have fallen in short time span. Thus activity rate may be based partly on geological and partly on historical data (Woo [27]) and the density of each cell is calculated from eqn. (7). As an example, to show the earthquake densities, in the fig. 3, the historical earthquakes and faults, densities calculated from earthquake data and faults individually, and combination of both are shown. For each fault, an equivalent earthquake represented by its maximum magnitude (Wells and Coppersmith [29]) was assigned to calculate the density. The densities calculated from the historical earthquakes are higher around the regions where great 
earthquakes have occurred in the past whereas the densities calculated from maximum magnitude of fault are higher around the faults which account future possibilities of occurrence even though there might not be the records of historical earthquakes and combination of two accounts both past history and future possibilities.

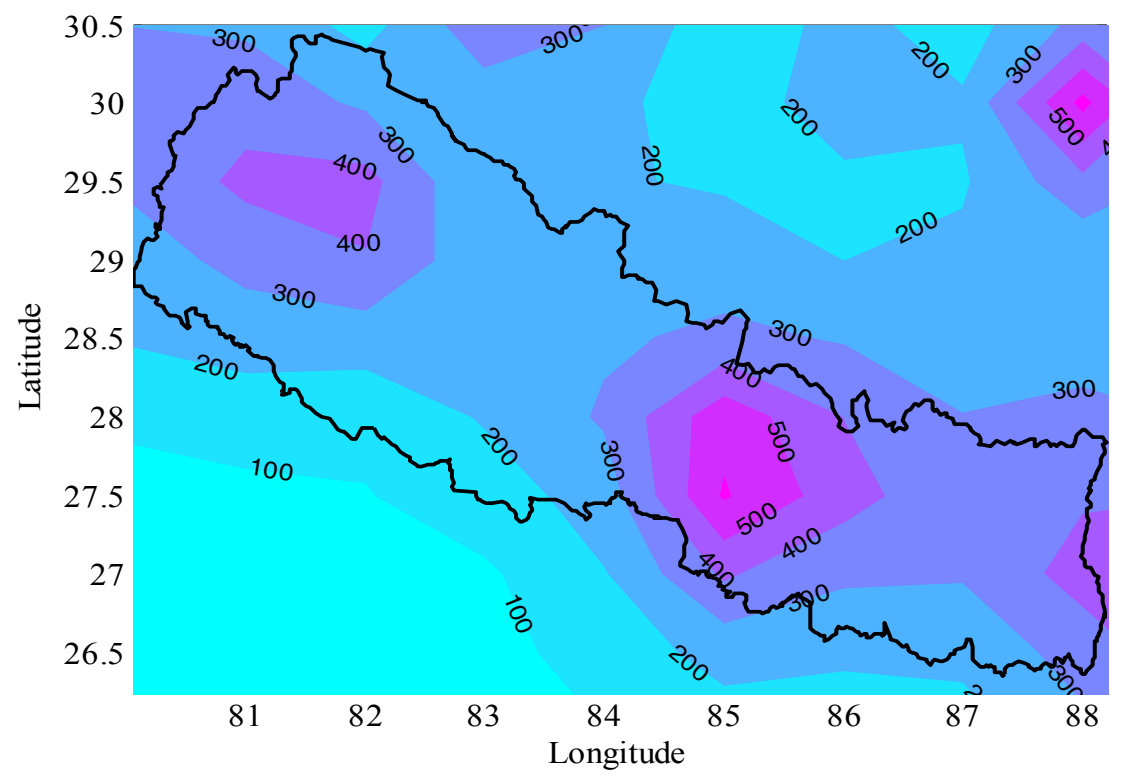

Figure 3: $\quad$ PGA (soft soil - 5\% damping and 10\% in 50 years).

Magnitude is divided into $0.1 \mathrm{M}$ and distance into $10 \mathrm{~km}$ intervals. $\mathrm{N}_{\mathrm{m}}$ and $\mathrm{N}_{\mathrm{r}}$ are the total numbers of magnitude and distance bins. Thus, the mean rate of occurrences can be obtained by eqn. (8).

$$
v_{y^{*}}=\sum_{i=1}^{N_{S}} \sum_{j=1}^{N_{r}} \sum_{k=1}^{N_{m}} v_{i_{M \min }} \rho_{i} P\left[Y>y^{*} \mid m, r\right] P[M=m] P[R=r] \Delta m \Delta r
$$

\subsection{Maximum magnitude}

In the seismic hazard assessment another important parameter is maximum magnitude. In the earthquake catalogue, maximum earthquake size is M8.2. However, recent study [30] has shown that big earthquakes M8.8 should have occurred in the same area where the 1934 Nepal-Bihar earthquake occurred. Though, it still requires further investigation to determine its exact size and location, it give there is possibility of bigger earthquake. Thus, in this study, maximum earthquake is considered as M8.8.

\section{Probabilistic spectra}

Mean rate of exceedences for peak ground accelerations and various spectral accelerations are calculated from five attenuation laws. Considering earthquake 
occurrences follow Poisson's process, accelerations for three probabilities of exceedences in 50 years were calculated from all attenuation laws at each site, and combined together giving equal weights. Peak ground acceleration of 10 probabilities of exceedences in 50 years (475 years return period) in soft soil condition for $5 \%$ damping obtained at various sites is plotted fig. 3 . The values shown in the contours are in gals. PGA for distribution is higher around Kathmandu than in other part of the country (fig. 3). PGA of 500 gals near Kathmandu, 400 gals in western part and around 300 gals in the remaining part of the country are obtained.

To compare the results the highest values (soil group 2) from BECA 1993 among three types of soil conditions are taken and the results obtained from this study are plotted together in fig. 4. The purpose of using return period $100(39 \%$ in 50 years-100 RT yrs.-fig 4), 475 (10\% in 50 years- 475 RT -fig. 4) and 1000 (4.85\% in 50 years-1000 RT yrs.-fig. 4) years is to make clarity with BECA [3]. In the plotting values in the horizontal axis are natural periods in seconds and in the vertical axis accelerations are in the fraction of $\mathrm{g}$ (acceleration due to gravity).

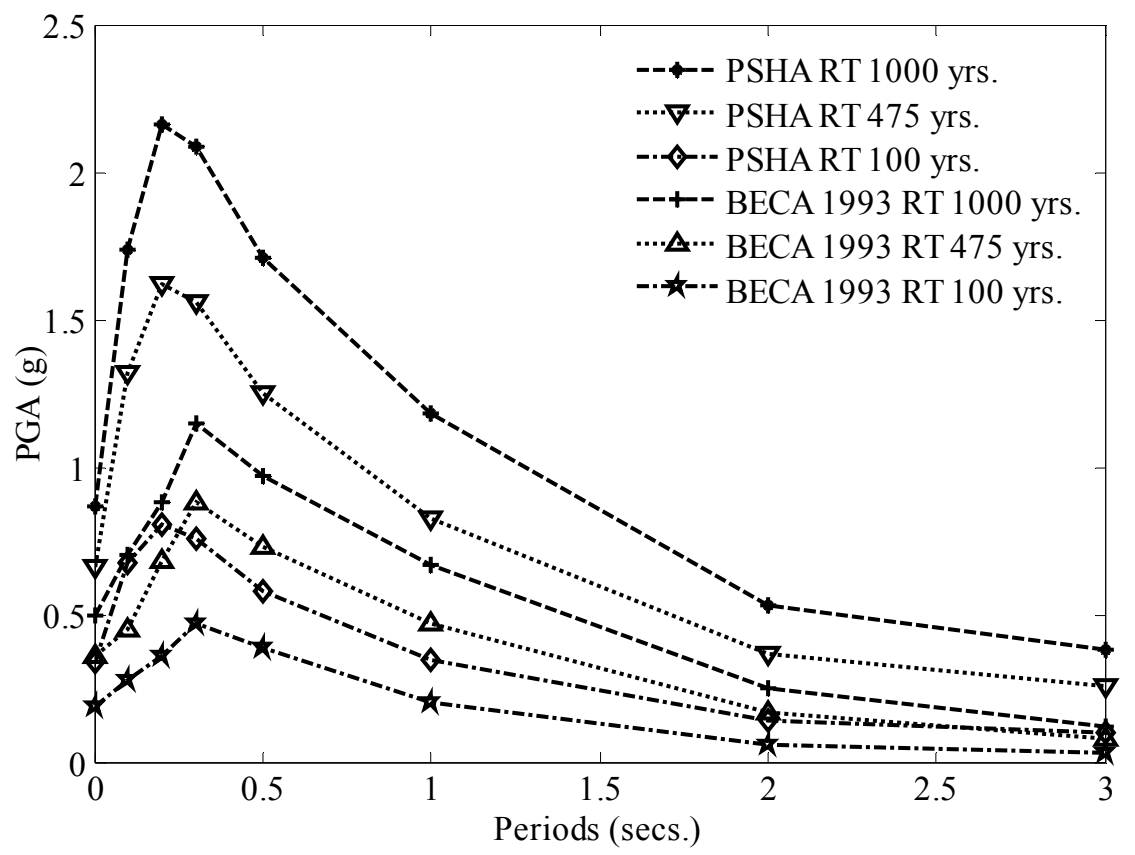

Figure 4: Comparison of spectra for Kathmandu.

\section{Discussion and conclusions}

In the fig. 3, higher concentration around Kathmandu can be seen than other part of the country illustrating the highest risk. However, in the western part, the 
PGA seems lower. The reason might be more historical earthquake records are available in the central part than other areas. Kathmandu has very soft soil and ground motions would have been amplified very much than in other places and the people would have thought earthquake occurred near or in the Kathmandu which might be the case all the earthquake records centred near Kathmandu. This kind of misinterpretation is very likely because similar case happened in 1934 earthquake. Because of the soft alluvium deposit in the Ganges plain, heavy damage occurred in Bihar and earthquake was supposed to occur in Bihar [4] in the beginning. But, it was relocated at $10 \mathrm{~km}$ south of Mount Everest later [31]. However, the relocation of earthquakes within few kilometres does not make any significant differences in hazard estimates. The recent investigations [17] based upon GIS reveals that there is big seismic gap especially in the western part of Nepal Himalaya. Available earthquake data supports only one third of its slip rate. There are many possible alternate explanations for that. Earthquakes may have gone missing, the slip between the two plates may be aseismic that could die out without producing any earthquakes or earthquake may occur soon. Thus, despite smaller values obtained from the analysis, for design and code implementation purpose, it is better to consider similar values as obtained near Kathmandu.

In fig. 4, the peaks are not aligning in the same axis. This means that different attenuation laws estimate peak values of spectral acceleration at different periods. Each attenuation laws have been developed upon its own hypothesis and tectonic environment. They have different earthquake database, use different distances such as distance from site to faults surface, epicentre, hypocentre, rupture location etc. The depth has also significance on the functional form of attenuation laws. Thus, slight differences in the results by different attenuation laws are obvious. Almost all of the recent attenuation laws developed for subduction zones have used depth and interface and intra-plate events as separate variables in the equations which have not been used in Kawashima et al. [7] equation.

Site soil classifications also give significant effects to the results. As the period of vibration increases the contributions of bigger events go on increasing. BECA [3] does not consider events greater than M8, thus it may be the other reason for not aligning the peaks. It has increased earthquakes data by 2.5 times and has distributed the density uniformly in subzones. This may be the cause giving different results. Despite there may be several reasons for differences in the results, previous study lacks to incorporate recent information and presents far lower than the seismic hazard intensity that Kathmandu has. Thus, there is an urgent need to revise the existing hazard estimate and code provisions.

\section{References}

[1] Molnar, P., Structures and tectonics of Himalaya: Constraints and implication of geophysical data. Ann. Rev. Earth Planet Sci. 489-518, 1984.

[2] Avouac, J. P., Mountain building, erosion, and the seismic cycle in the Nepal Himalaya. Advances in Geophysics, Elsevier Inc, 46, 2003. 
[3] BECA World International (New Zealand) in association with SILT Consultants (P.) Ltd. (Nepal), TAEC Consult (P.) Ltd. (Nepal), Golder Associates (Canada) and Urban Regional Research (USA), Seismic Hazard Mapping and Risk Assessment for Nepal, 1993.

[4] Rana B. S. J. R., Nepal's Great Earthquake 1934 (in Nepali). Sahayogi Press, Tripureshwor, Kathmandu, 1935.

[5] Ambraseys, N. and Jackson, D., A note on early earthquakes in Northern India and Southern Tibet. Current Science, 84(4), 2003.

[6] Maskey, P. N. and Datta, T. K., Risk consistent response spectrum and hazard curve for a typical location of Kathmandu valley. 13th world conference on earthquake engineering, Vancouver, B.C., Canada, Aug.1-6, 3124, 2004.

[7] Kawashima, K., Aizawa, K. and Takahashi, K., Acceleration of peak ground motion and absolute acceleration response spectra. Proc., Eight World Conference on Earthquake engineering, San Francisco, 2, 257-264, 1984.

[8] Japanese International Cooperation Agency (JICA), The study on earthquake disaster mitigation in the Kathmandu valley, Kingdom of Nepal, 2002.

[9] Parajuli, H., Kiyono, J., and Scawthorn, C., Probabilistic seismic hazard assessment of Kathmandu. Proceedings of twentieth KKCNN symposium on civil engineering, Jeju, Korea, Oct., 2007.

[10] Parajuli, H., Kiyono, J., Ono, Y. and Tsutsumiuchi T., Design earthquake ground motions from probabilistic response: Case study of Nepal. Journal of Japan Association for Earthquake Engineering, 8(4), November, 2008.

[11] USGS, http://earthquake.usgs.gov/earthquakes/eqarchives/epic/epic_rect.php.

[12] Pant, M. R., A step towards historical seismicity of Nepal. Fransco-Nepal conference on people, environment and landscape of Himalayas, 20 April, 2000.

[13] Ambraseys, N. N. and Douglas, J., Magnitude calibration of north Indian earthquakes. Geophysics. J. Int., 159, 165-206, 2004.

[14] Hank, T. C. and Kanamori, H., A moment magnitude scale. Journal of Geophysics Res., 84, 2348-2350, 1979.

[15] Mcguire, R. K., Seismic hazard and risk analysis. Earthquake Engineering Research Institute, MNO-10, 2004.

[16] Stepp, J., Analysis of completeness of the earthquake sample in the Pudet Sound area and its effect on statistical estimates of earthquake hazard. Proceedings of the first microzonation conference, pp. 897-909, Seattle, WA, 1992.

[17] Bilham, R. and Ambraseys, N., Apparent Himlayan slip deficit from the summation of seismic moments for Himalayan earthquakes. Current Science, 88(10), 1658-1663, 2005.

[18] Crouse, C. B., Ground-motion attenuation equations for earthquakes on the Cascadia Subduction zone. Earthquake spectra, 7(2), 1991. 
[19] Fukushima, Y. and Tanaka, T., A new attenuation relation for peak horizontal acceleration of strong earthquake ground motion in Japan. Bulletin of Seismological Society of America , 80(4), 757-783, 1990.

[20] Molas, G.L. and Yamazaki, F., Attenuation of earthquake ground motion in Japan including Deep focus events. Bull. Seismol. Soc. Am., 85, 1343-1358, 1995.

[21] Youngs, R.R, Chiou, S.J, Silva, W.J and Humhrey, J.R.,Strong ground motion attenuation relationships for subduction zone earthquakes. Seismological Research Letters, 68(1), 58-73, 1997.

[22] Gregor, N. J., Silva, W. J., Wong, I. G. and Youngs, R. R., Ground-motion attenuation relationships for Cascadia subduction zone. Bull. Seismol. Soc. Am., 92(5), 1923-1932, 2002.

[23] Atkinson, G.M. and Boore, D.M., Empirical ground-motion relations for subduction-zone earthquakes and their application to Cascadia and other regions. Bull. Seismol. Soc. Am., 93(4), 1703-1729, 2003.

[24] Atkinson, G.M. and Boore, D.M., Erratum to empirical ground-motion relations for subduction-zone earthquakes and their application to Cascadia and other regions. Bull. Seismol. Soc. Am., 98(5), 2567-2569, 2008.

[25] Kanno, T., Narita, A., Morikawa, N., Fujiwara, H., and Fukushima, Y., A new attenuation relation for strong ground motion in Japan based on recorded data. Bull. Seismol. Soc. Am., 96(3), 879-897, 2006.

[26] Zhao, J. X., Zhang, J., Asano, A., Ohno, Y., Oouchi, Takahashi, T., Ogawa, H., Irikura, K., Thino, H. K., Somerville, P. G., Fukushima, Y., and Fukushima, Y., Attenuation relations of strong ground motions in Japan using site classification based upon predominant period. Bull. Seismol. Soc. Am., 96(3), 898-913, 2006.

[27] Woo, W., Kernel estimation methods for seismic hazard area source modeling. Bull. Seismol. Soc. Am., 86(2), 353-362, 1996.

[28] Chen, Y., Liu, J., Chen, L., Chen, Q., and Chan, L.S., Global seismic hazard assessment based on area source model and seismicity data. Natural Hazards, Kluwer Academic Publishers, 17, 251-267, 1998.

[29] Wells, D.L. and Copersmith, K.J., New empirical relationships among magnitude, rupture length, rupture width, rupture area, and surface displacement. Bull. Seismol. Soc. Am., 84(4), 974-1002, 1994.

[30] Lave, J., Yule, D., Sapkota, S., Basnet, K., Madan, C., Attal, M. and Pandey, R., Evidence for a great medieval earthquake (1100 A.D.) in the central Himalayas, Nepal. Science, 307, 2005.

[31] $1934 \mathrm{Mw} 8.1$ Bihar/Nepal earthquake 15 January 1934, http:/cires.colorado.edu/ bilham/HimalayanEarthquakes/1934BiharNepal/ 1934earthquake.html.

[32] Kramer, S.L. (1996). “Geotechnical earthquake engineering.” Prentice-Hall International series in Civil Engineering and Engineering Mechanics 